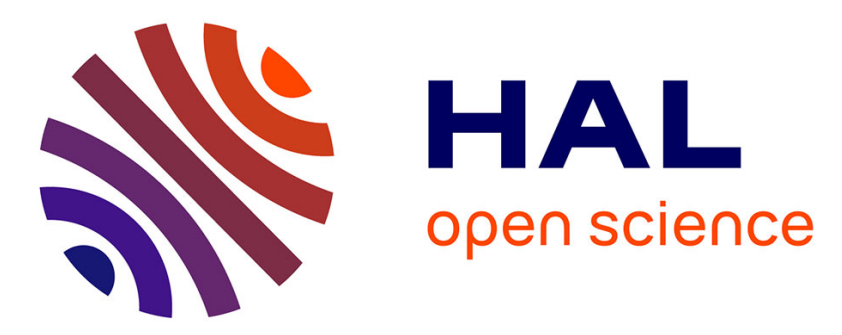

\title{
INFLUENCE OF THE DEPLETED ZONE ON THE EBIC CONTRAST: A SIMPLE DERIVATION. APPLICATION TO THE DISLOCATION AND GRAINBOUNDARY CASES
}

\author{
D. Mekki, R. Tarento
}

\section{To cite this version:}

D. Mekki, R. Tarento. INFLUENCE OF THE DEPLETED ZONE ON THE EBIC CONTRAST: A SIMPLE DERIVATION. APPLICATION TO THE DISLOCATION AND GRAINBOUNDARY CASES. Journal de Physique IV Proceedings, 1991, 01 (C6), pp.C6-63-C6-69. 10.1051/jp4:1991611 . jpa-00250696

\section{HAL Id: jpa-00250696 https://hal.science/jpa-00250696}

Submitted on 1 Jan 1991

HAL is a multi-disciplinary open access archive for the deposit and dissemination of scientific research documents, whether they are published or not. The documents may come from teaching and research institutions in France or abroad, or from public or private research centers.
L'archive ouverte pluridisciplinaire HAL, est destinée au dépôt et à la diffusion de documents scientifiques de niveau recherche, publiés ou non, émanant des établissements d'enseignement et de recherche français ou étrangers, des laboratoires publics ou privés. 


\title{
INFLUENCE OF THE DEPLETED ZONE ON THE EBIC CONTRAST: A SIMPLE DERIVATION. APPLICATION TO THE DISLOCATION AND GRAINBOUNDARY CASES
}

\author{
D.E. MEKKI and R.J. TARENTO \\ Laboratoire de Physique des Matériaux, 1 Place A. Briand, \\ CNRS, Bellevue, F-92195 Meudon Cedex, France
}

\begin{abstract}
The present article deals with a simple derivation of the modelisation of the EBIC contrast. It takes account of the recombination in the depleted zone (recombination velocity and finite diffusion length). It has been applied to the dislocation and grain boundary cases.
\end{abstract}

1 - Introduction

The VLSI technology of semiconductor devices has stimulated research on ponctual and extended defects (i.e. : chiefly the electrical properties). The EBIC technique has been intensively applied to image defects by studying the contrast [1]. However, the derivation of the defect characterization (i.e. electronic level distribution, recombination cross-section) is linked to the accuracy of the contrast modelisation; i.e. : the solution of the continuity equations for holes and electrons taking account of the boundary conditions. A general formali'sm is not possible and moreover some simplifications have been often assumed. In particular the physical processes involved in the depleted zone are often neglected by considering a concentration equal to zero at the interface between the depleted and the neutral zones. However BRESSE et al [2] have pointed out the importance of the interface states on the recombination. In the same way the study of the EBIC collection efficiency (Au/n-Ge diodes [3]) has confirmed that the recombination within the depleted zone is essential to explain the experimental results. Moreover a theoretical study of the influence of the depleted zone on the EBIC contrast given by a defect has been carried out within the BORN approximation framework [4]. However the formalism is not straightforward. So the present article derives a simple model which takes account of the depleted zone and which is mathematically easy to use. The present work is based on the new modelisation of the EBIC collection eficiency [5] which is quickly described in part 2. The part 3 deals with the contrast problem.

2 - A new and simple model for the ebic collection efficiency

In a previous article [5], the new model developped for the EBIC collection efficiency has been presented, so only the essential features are described. In a pionneer work, WU and WITTRY have assumed that the current $J$ is the sum of two contributions due to the carriers created either in the depleted zone $\left(\mathrm{J}_{0}^{1}\right)$ or in the neutral zone $\left(\mathrm{J}_{0}^{2}\right)[6]$. Moreover they consider that the carrier concentration is zero at the interface between the neutral and depleted zones and they neglect the recombination in the depleted zone. 
To include the recombination process it is convenient to assume an effective recombination velocity (Vs) at the neutral-depleted zone interface. Therefore the diffusion component of $J$ (i.e. : the neutral zone one) is :

$$
\mathrm{J}^{2}=\frac{\mathrm{S}}{\mathrm{S}+1} \mathrm{~J}^{2}
$$

where $J_{0}^{2}$ is the WU-WITTRY diffusion term, and $S$ is for a $n$ doped semiconductor given by :

$$
S=V S \frac{L P}{D P}
$$

with $L p$ and Dp the minority carrier diffusion length and diffusion coefficient. In eqn. 1 , the coefficient $S / S+1$ can be interpreted as the recombination probability at a depth $\mathrm{Z}=\mathrm{Zd}$ ( $\mathrm{Zd}$ is the depleted zone depth). The component $\mathrm{J}^{1}$ due to the carrier yielded in the depleted zone is

$$
J^{1}=-q \int_{0}^{z d} r(z) g(z) d z
$$

where $g(z)$ is the generation function and $r(z)$ the carrier recombination at the depth $z$ which is assumed to follow a HECHT law [7]. Hence

$$
\gamma(z)=\frac{1}{(S+1)\left(1-\exp \left(-z \alpha / L^{\prime}\right)\right)}\left(S-(S+1) \exp \left(-z d / L^{\prime}\right)+\exp \left(-z / L^{\prime}\right)\right)
$$

where $L^{\prime}$ is the diffusion length in the depleted zone. A comparison of the new EBIC efficiency with a previous one [3] which solves the continuity equations both in the neutral and depleted zones has shown that the derived data (diffusion length) are in a good agreement if we compare to the experimental error. So the good agreement for the collection efficiency has incited us to examine the contrast case.

3 - The contrast model

Like for the EBIC collection efficiency, the contrast is the sum of two contributions (i.e. : one is given by the carrier created in the depleted zone (C1) and another due to the carrier produced in the neutral zone (C2).

\subsection{Contribution of the neutral zone to the contrast $C 2$}

Without defect, the measured current due to the neutral zone is given by the diffusion component and is

$$
i_{0}^{2}=V_{s} \iint_{S_{1}} d x d y \quad \Delta P_{0}(x, y, z d)
$$


where $\mathrm{S} 1$ is the surface of the neutral depleted zone interface and $\triangle \mathrm{PO}$ is the concentration at the neutral depleted zone interface. Moreover, $\triangle P O$ is 1 inked to the Green function $G^{\circ}(\vec{r}, \vec{r})$ and the generation function $g(\vec{r})$ by

$$
\Delta P_{0}(\vec{r})=\int_{\text {neutral volume }} \frac{g\left(\overrightarrow{r^{\prime}}\right)}{D P} G^{0}\left(\vec{r}, \overrightarrow{r^{\prime}}\right) d \vec{r}^{\prime}
$$

Let us focuss on the defect influence on the current, let us apply the MAREK formalism [8] (i.e. : the defect is a set of points with a life time $\tau^{\prime}$ different from the bulk one $\tau$ ). So for the grainboundary case, the difference of current Di(X, $\mathrm{Y}$ ) with and without a defect located at the point (X, Y) (fig.1) is

$$
\Delta i z(X, Y)=\frac{V s}{D}\left(\frac{1}{\tau},-\frac{1}{\tau}\right) \Delta P o(X, 0, Z) \iint G^{O}(x, y, z D, X, O, Z) d x d y
$$

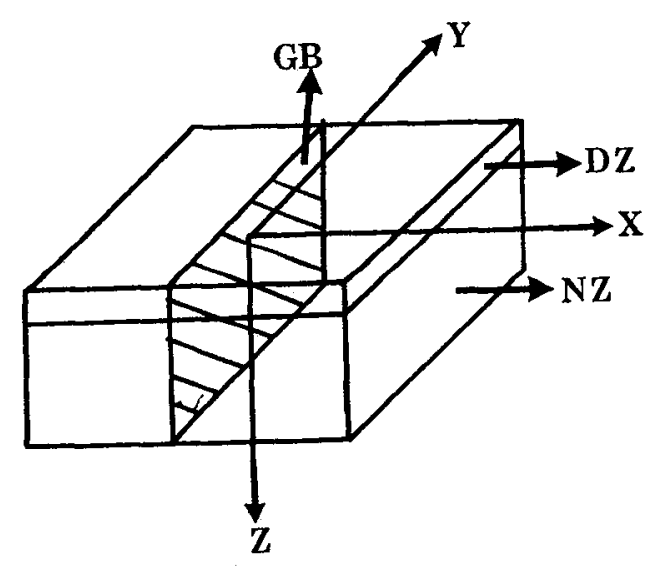

Fig.1 : Geometrical structure of the grainboundary (GB) problem $\mathrm{Dz}=$ depleted zone, $\mathrm{Nz}$ : neutra1 zone

(the generalization to other types of defects is straightforward). Therefore the contrast for a grainboundary is

$$
C_{2}=\iint_{\text {grainboundary }} \frac{\Delta i z}{i 2}(X, Y) d X d Y
$$


In eqn. 6 a BORN approximation has been considered, i.e. : the Green function of the unperturbated crystal is involved instead of the one the defectuous crystal. In the case where the parameter $S$ (eqn. 2) is large, $G^{\circ}$ has an asymptotic form

$G\left(x, y_{1} z, x^{\prime}, y^{\prime}, z^{\prime}\right)=\frac{1}{4}=\left\{\frac{\exp \left(-R_{1}\right)}{R_{1}}+\frac{\exp \left(-R_{2}\right)}{R_{2}}-^{2} \frac{\exp \left(-R_{2}\right)}{R_{2}}\left(1-\frac{(z+z P) / L)}{\alpha R_{2}^{2}}\right) \frac{1}{\alpha R_{2}}\right\}$

whereR $1=\left(\left(x-x^{\prime}\right)^{2}+\left(y-y^{\prime}\right)^{2}+\left(z-z^{\prime}\right)^{2}\right)^{1 / 2}$

$$
R \quad z=\left(\left(x-x^{\prime}\right)^{2}+\left(y-y^{\prime}\right)^{2}+\left(z+z^{\prime}\right)^{2}\right)^{1 / 2}
$$

and $\alpha=1+\frac{\left(z+z^{\prime}\right)}{R 2 S I}$

The generation function $g(r)$ is taken of the following form

$$
g(r)=g_{\Gamma 1}^{0} \frac{\left(z / \Gamma_{1}\right)}{2 \pi \sigma^{2}(z, r 1)} \quad \exp \left(-\frac{r^{2}}{2 \sigma^{2}(z, r 1)}\right)
$$

$\mathrm{r} 1$ is the Gruen range $\left(\mathrm{r} 1=\frac{4.57 \times E 0^{1.75}}{\rho \times 100}(\mu \mathrm{m})\right)$, where Eo is the electron beam energy [9] in keV, $\rho$ the material density in $\mathrm{g} / \mathrm{cm}^{3}, \mathrm{~g}^{\circ}$ is the total generation rate and $\sigma$ is the lateral Gaussian function width [10]

$$
\sigma^{2}(z, r 1)=0.11 z^{3} / r 1
$$

$\wedge(z / r 1)$ is the depth dose relationship derived by EVERHART and HOFF [11].

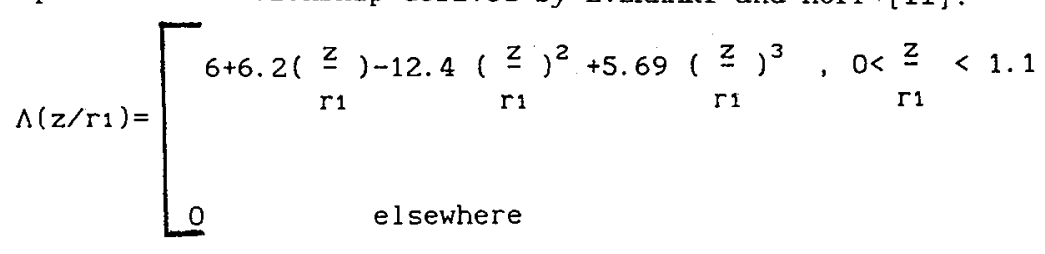

The figure 2 displays the contrast versus the energy of the electron beam for different recombination velocity at the grainboundary and at the dislocation for a diffusion length $\mathrm{Lp}$ equal to $15 \mu \mathrm{m}$. It is worth noticing that for recombination velocity less than $V t h / 10$ the dependence is significant and the effect is more drastic for the dislocation case. 


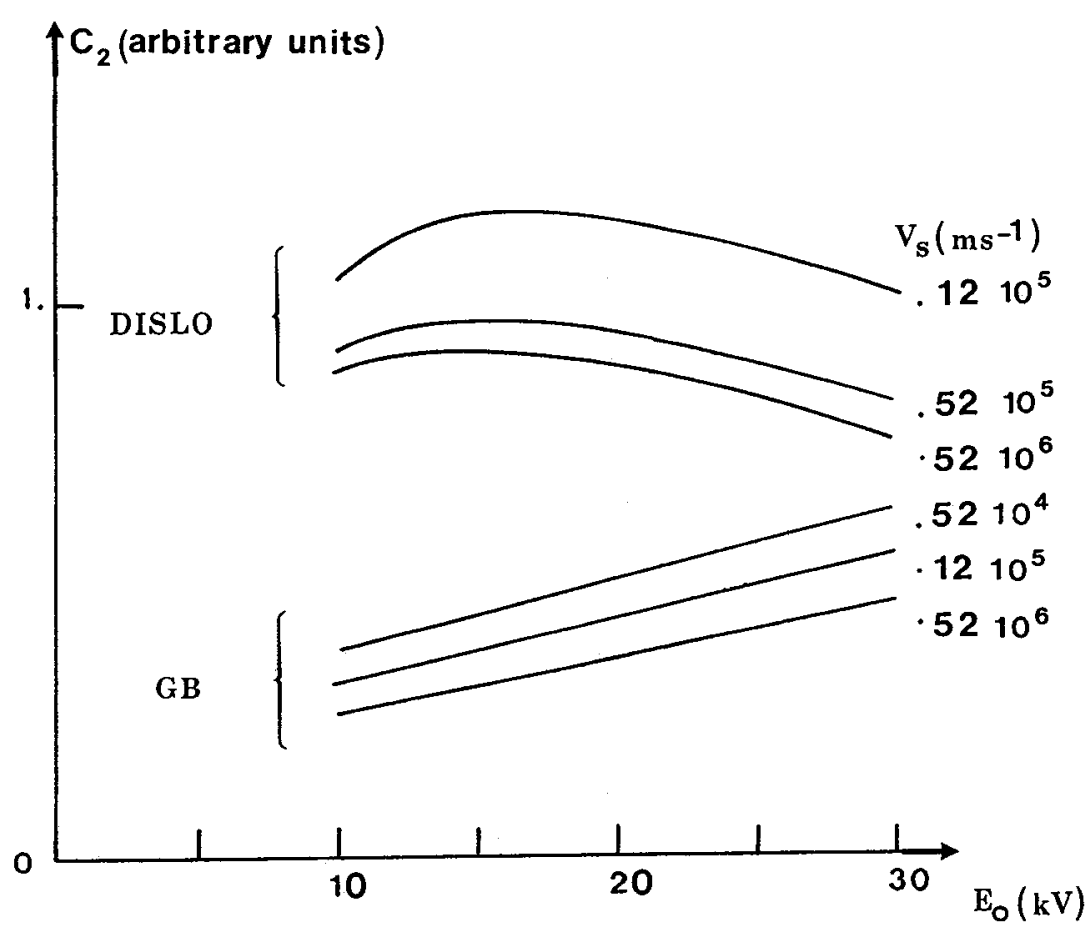

Fig. 2 : Grainboundary and dislocation EBIC contrast C2 due to the contribution of the carriers created in the neutral zone

\subsection{Contribution of the depleted zone on the contrast $\mathrm{Cl}$}

In the depleted zone, the trajectories of the carrier are straight lines (along the lectric field). So in the case with no defect the current which is due to the carrier produced in the depleted zone is

$$
j 1=-q \int_{V D} \gamma(z) g(\vec{r}) \overrightarrow{d r}
$$

where $\gamma(z)$ has been determined in eqn. 4, Vd is the depleted zone volume.

Let us consider the case where a defect is present, the current could be written as

$$
j_{1}=-q \int_{V D} \gamma(z) C(x, y, z b) g(\vec{r}) \overrightarrow{d r}
$$

where $C(x, y, z d)$ is by continuity defined by

$$
C(x, y, z D)=1-C 2(x, y)
$$

So the contrast $\mathrm{Cl}$ due to the carriers yielded in the depleted zone is

$$
C_{1}=\frac{\int_{V_{D}} \gamma(z) C_{2}(x, y) g(\vec{r}) \overrightarrow{d r}}{\int_{V_{D}} \gamma(z) g(\vec{r}) \overrightarrow{d r}}
$$


Therefore the contrast $\mathrm{C}$ is given by the sum of the two contributions

$$
C=C_{1}+C_{2}
$$

In fact the evolution of the contrast $C$ looks like the $\mathrm{Cz}$ one (fig. 2), so only the defect strength will differentiate experimental fits obtained with eqn. 7 and 17 . So to have more information we have to study the current dependence on the distance from the defect. The figure 3 displays the different contributions for the dislocation case and it shows that the knowledge of the spatial dependence is very important to derive information.

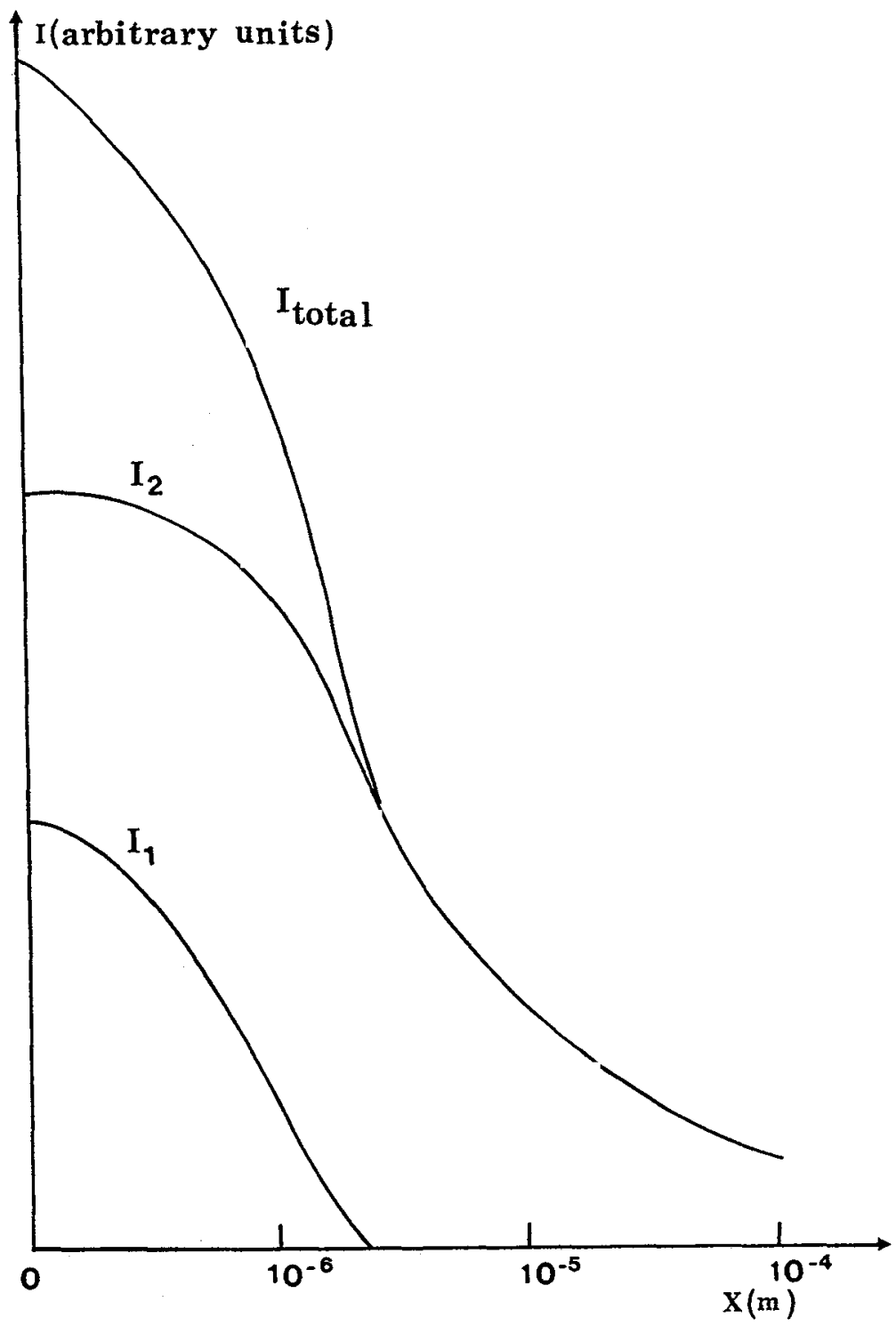

Fig. 3 - Spatial dependence of the dislocation EBIC currents $I_{\text {tot }}$ and for the components $I_{1}$ and $I_{2}$ due to the contributions of the carriers generated in the depleted zone or in the neutral zone 
The model proposed is simple and allows to obtain some characterization of the recombination. It will be interesting to compare the results derived by the model with a more accurate one.

\section{References}

1/ BIADS 88, Rev. Phys. Appl., 24, C6 (1989).

/2/ PERANSIN, J.M., DA SILVA and BRESSE J.F., Phys. Stat. Sol(a), 94, (1986) 713.

13/ TABET, N. and TARENTO, R.J., Phil. Mag., B 59 (1989) 243.

14/ MEKKI, D., TARENTO, R.J. and TABET, N., to be published.

16/ WU, C.J. and WITTRY, D.B., J. Appl. Phys., 49 (1978) 2827.

/7/ HECHT, K., Z Phys., 77 (1932) 2356.

/8/ MAREK, J., J. App1. Phys., 53 (1982) 1454.

19/ Quantitative Scanning Electron Microscopy, Eds D.B. Holt et al (Academic Press (1974) p. 57)

/10/ DONOLATO, C. Phys. Stat. Sol. (a), 65 (1981) 5827.

/11/ EVERHART, T.E. and HOFF, P.H., J. App1. Phys., 91 (1971) 5827. 